\title{
HRM Solutions for Retaining Millennials in Western Societies
}

\author{
Sandra K. Cassell \\ DBA Student, \\ Anderson University
}

Doi: $10.1515 / m j s s-2017-0032$

\begin{abstract}
Organizations and researchers in Western societies are finding employees belonging to the Millennial generation are harder to retain than were employees of previous generations. Using generation theory for the foundation, this paper first looks at the literature discussing whether generational cohorts should continue to be defined as nationally bounded entities, or whether there are now 'global generations' in existence. Then, factors that decrease employee turnover are explored. Using social exchange theory and the norm of reciprocity as the basis, the literature suggests affective commitment leads to reduced turnover intentions. Two major constructs found to increase affective commitment are perceived supervisor support (PSS) and perceived organizational support (POS). Finally, human resource management (HRM) antecedents of PSS and POS identified as important by Millennials in Western societies are submitted as potential solutions for retaining employees of the Millennial generation.
\end{abstract}

Keywords: Millennials, Human Resource Management (HRM), Perceived Supervisor Support (PSS), Perceived Organizational Support (POS), Affective Commitment

\section{Introduction}

The topic of employee retention and the antecedents that lead to decreased turnover intentions has been the subject of extensive organizational research (Allen, Shore, \& Griffeth, 2003; Dawley, Andrews, \& Bucklew, 2008; DeConinck \& Johnson, 2009; Du Plessis, Barkhuizen, Stanz, \& Schutte, 2015; Eisenberger, Stinglhamber, Vandenberghe, Sucharski, \& Rhoades, 2002; Maertz, Griffeth, Campbell, \& Allen, 2007). Human capital is viewed as one of the most important assets an organization controls and retaining talent is thought to be a crucial element for sustained competitive advantage and overall organizational success (Barney, 1991). Unfortunately, many organizations in Western societies believe it is becoming harder to retain valuable employees. Current academic research performed in the United States, Canada, Europe, Australia, and South Africa backs up practitioner claims that organizational loyalty, which was common among the now retiring Baby Boomer generation, is not being carried forward into successive generations (Allen, 2004; Barkhuizen, 2014; Becton, Walker, \& Jones-Farmer, 2014; D'Amato \& Herzfeldt, 2008; Du Plessis, 2010; Du Plessis et al., 2015; Maertz et al., 2007). In fact, studies have indicated that the generation currently coming of age and entering the workforce, the Millennial generation, is the most professionally mobile generation to date (Barkhuizen, 2014; Bassett, 2008; Becton et al., 2014; Du Plessis et al., 2015; Eisner, 2005; Tulgan, 2009).

Given the high costs associated with recruiting and training new employees, along with the loss of productivity from losing seasoned employees, organizations and researchers are attempting to understand what specifically motivates Millennial employees to stay (DeConinck \& Johnson, 2009; Rhoades, Eisenberger \& Armeli, 2001; Tulgan, 2009). Research suggests that employee perceptions of supervisor support (PSS) and employee perceptions of organizational support (POS) 
influence voluntary turnover intentions through their impact on affective organizational commitment and that strengthening these perceptions of support is a primary tool for managing turnover (Allen et al., 2003; DeConinck \& Johnson, 2009; Eisenberger, Armeli, Rexwinkel, Lynch, \& Rhoades, 2001; Eisenberger et al., 2002; Kurtessis et al., 2015; Maertz et al., 2007; Meyer \& Allen, 1991; Rhoades et al., 2001; Rhoades \& Eisenberger, 2002; Wayne, Shore, \& Liden, 1997).

A key strategy found to strengthen employee perceptions of support is implementation of human resource policies and practices that align with employee preferences (Smit, Stanz, \& Bussin, 2015). The question this paper attempts to answer is what particular HRM practices have been empirically shown to be desired by Millennial employees in Western societies. The paper will be organized as follows. The first section will review the literature on Generation Theory, focusing first on how generational cohorts are defined, and then migrating into a summary of the characteristics and workplace preferences of the Millennial generation. The second section will review the literature on organizational commitment along with its consequences and antecedents to present a conceptual framework. Finally, HRM practices and policies that align with values and workplace expectations of Millennials in Western societies will be identified as potential solutions for reducing turnover.

\section{Generational Literature Review}

\subsection{Generation Theory}

Terms such as Baby Boomers, Gen Xers, and Millennials are a product of Generation theory. The seminal work on Generation theory was a 1928 essay, The Problem of Generations, written by German sociologist Karl Mannheim. This work was translated and published in English in 1952 (Espinoza \& Ukleja, 2016; Mannheim, 1952).

Generation theory submits that a generational cohort is created and defined by two elements. First, a cohort shares a common range of birth years that typically spans between 15-20 years. Second, the cultural influences experienced during a generation's formative years such as parenting styles, music, movies, clothes, and technology along with significant historical events and political movements create a collective memory and unique bond for members of each cohort. These common experiences shape the attitudes and core values of the generation and produce unique characteristics, behaviors, and a worldview which differs from previous generations (Espinoza \& Ukleja, 2016; Parry \& Urwin, 2011).

Generational attitudes and values have important implications for society and for businesses. As each generation comes of age, they transform society by challenging currently accepted norms and establishing new cultural norms that align with their own values and preferences. In addition, when the generation enters the workplace, their distinctive values and work preferences influence organizational culture and the policies that are established (Allen, 2004; Espinoza \& Ukleja, 2016; Finegold, Mohrman, \& Spreitzer 2002; Parry \& Urwin, 2011). Therefore, understanding the unique way a generation is wired provides valuable information for those attempting to harness their potential.

Academic literature as well as the popular press have published vast amounts of articles and books on the three generations currently active in today's workforce (Becton et al., 2014; Cennamo \& Gardner, 2008; Twenge, 2010; Zopiatis et al., 2012). The majority of generation research has been conducted in Western societies such as the United States, Canada, Europe, Australia, and South Africa (Barkhuizen, 2014; Becton et al., 2014; Cennamo \& Gardner, 2008; Lyons et al., 2012). Although there are slight variations between studies when defining birth years, research conducted in Western societies generally operationalizes cohort designations currently active in the workforce by the following titles and birth years:

\begin{tabular}{|l|c|}
\hline Generation Title & Birth Years \\
\hline Baby Boomers & $1946-1964$ \\
\hline Generation X & $1965-1980$ \\
\hline Millennials or Gen Y & $1981-1999$ \\
\hline
\end{tabular}




\subsection{Global Generations}

Mannheim's 1928 seminal work on Generation theory conceptualized generational cohorts as nationally bounded entities and the majority of generation research since then has continued within that same framework. Recently though, several authors in the Management literature have put forth the idea that perhaps generations should now be defined more globally (Aroldi \& Colombo, 2013; Aroldi \& Ponte, 2012; Edmunds and Turner, 2005; Parry \& Urwin, 2011; Volkmer, 2006).

According to Generation theory, cohorts are formed as youth share in significant cultural and historical experiences. Therefore, there must be some form of proximity to the events or cultural phenomena. During the era of Mannheim's writings, shared experiences usually occurred from having direct proximity to the event or culture. However, today the media and the Internet mediate a sense of shared experiences without being in direct proximity. According to Edmunds and Turner (2005), generations migrated from being simply nationally defined to being globally defined during the 1960's when the news media began transmitting events such as the Vietnam War across the globe. The media connected people in developed countries with each other and the events happening in Vietnam. This resulted in the youth cultures of the United States and Europe mobilizing global protests and sharing a transnational experience. D'Amato and Herzfeldt (2008) concur that there has been an emergence of global generations. Their research found that since the 1960's, the cohort demarcations in Europe have mirrored those used in North America primarily due to the increased communication across national borders that has been aided by technology.

Volkmer (2006) conducted an international study which compared three generations in nine different countries (Australia, Austria, The Czech Republic, Germany, India, Japan, Mexico, South Africa and the United States) to determine if there were similarities in shared experiences and memories due to international communication and news. His findings showed that "despite national, cultural and societal differences," media and global news had "created very similar generational experiences in the nine countries involved" (2006; p. 6). Similarly, Aroldi and Ponte (2012) compared two generations born in the same years in Italy and Portugal that grew up in varying economic and political environments to explore to what extent media shaped generational identities. They found that movies, radio, television, and especially music shaped similar generational narratives which led them to agree that transnational generational cohorts do exist.

Edmunds and Turner (2005) actually contend that there are currently two global generations: one that began in the 1960s, and one that began with 9/11. While the first global generation was primarily connected through access to the news media, the newest global generation is a result of the growth of the Internet and the prominence of mobile phones that can access the Internet from practically anywhere. This 'e-generation' or 'Internet generation' shares common experiences through viewing real-time images and videos of global events which can be understood regardless of potential language barriers. According to Edmunds and Turner (2005, p. 568) this new global generation includes "the USA, Canada and Europe, Asia and the Asian Pacific, Latin America, Africa and the Middle East."

In today's globally connected world, influential events such as "Chernobyl and 9/11, environmental crisis, and terrorist attacks" are no longer contained within national borders. In addition, sporting events and merchandise, movies and music from the entertainment industry, and consumer products are all being spread internationally "through production and markets, through media and advertising, migration, and tourism" (Beck and Beck-Gernsheim, 2009, p. 25). This transnational connectivity provides the foundation for the argument that it may be time for a paradigm shift from defining generations as nationally bounded to a more global orientation, particularly when trying to understand the younger generation, its orientations, and behaviors (Beck and Beck-Gernsheim, 2009).

Although there has been literature to support the concept of a 'global generation', there has also been research that would contend that generations are still best defined within national contexts, or at the very least, differentiating Eastern countries from Western countries (Egri \& Ralston, 2004; Murphy et al., 2004; Schewe \& Meredith, 2004). Murphy et al. (2004) examined generational differences in values between the US and Japan; Egri and Ralston (2004) compared the generational cohorts in the United States to the generational cohorts in China; and Schewe and 
Meredith (2004) compared generational cohorts in the United States, Brazil, and Russia. All three studies resulted in findings that support developing and defining generational cohorts within a national context based on the social, economic, and political events experienced rather than using a global generational designation.

The question of whether generational cohorts should continue to be defined nationally or should be expanded to consider transnational or even global cohorts is a relatively new topic requiring more research. It is reasonable, though, that as globalization continues to increase, the amount of connectivity and shared experiences across national groups will increase, leading to more acceptance of a global generational cohort (Parry and Urwin, 2011).

\subsection{Criticisms of Generation Research}

Generational research has been prominent in academic literature for almost a century and as is true with most streams of research, there are criticisms. The main criticism is that most generation research has been cross-sectional making it very difficult, if not impossible, to distinguish genuine cohort effects from age-related and/or period effects. Cohort or generational effects are attitudes, values, and behaviors that form from sharing common experiences with others of similar age. These effects generally stay consistent throughout a person's life. Age effects are developmental in nature and occur as a result of maturing both intellectually and physically. These effects do change as a person goes through different life-stages and occur regardless of the timeframe in which a person is born. Period effects influence people's values based on societal influences that exist at a particular point in time. Since these three factors are inter-related, most cross-sectional studies approach cohort analyses as a possible combination of cohort, age, and period effects (Parry \& Urwin, 2011).

Longitudinal research corrects the limitations found in cross-sectional research and there have been a few longitudinal studies to validate genuine differences among different generational cohorts (Smola \& Sutton, 2002; Twenge \& Campbell, 2008; Twenge, Campbell, Hoffman \& Lance, 2010). It should be noted though, that for organizations and HRM professionals who use the information generated from cohort research to help them attract and retain employees, cross-sectional versus longitudinal research is usually of little concern.

If workers born between certain dates can be shown to exhibit a certain set of values and attributes, the extent to which this is driven by cohort/generation effects (which will endure as this group ages) as opposed to age or period effects (which will be less enduring) is often not important to the practitioner audiences (Parry \& Urwin, 2011, p. 93).

\subsection{The Millennial Generation}

Millennials have been designated as a generational cohort and researched in many countries around the world including Australia, Belgium, Canada, Cyprus, New Zealand, South Africa, and the United States. The Millennial generation is generally defined as people born between 1980 and 2000 (Allen, 2004; Eisner, 2005). Forces that have shaped their worldview and values are globalization, technology, constant change, an abundance of information, being over parented and over rewarded, and the immediacy of everything (Eisner, 2005; Hershatter \& Epstein, 2010; Tulgan, 2009). These factors have produced a generation that is:

- Technologically-savvy (Allen, 2004; Bassett, 2008; Becton et al., 2014; Eisner, 2005; Hershatter \& Epstein, 2010; Hills, Ryan, Warren-Forward, \& Smith, 2013)

- Highly educated (Allen, 2004; Eisner, 2005)

- Praise-oriented (Espinoza \& Ukleja, 2016; Tulgan, 2009)

- Professionally mobile (Barkhuizen, 2014; Bassett, 2008; Becton et al., 2014; Du Plessis et al., 2015; Eisner, 2005; Twenge, 2010)

Millennials also have been found to have certain preferences regarding their professional careers:

- Money is just a threshold factor of employment (Allen, 2004; Barkhuizen, 2014) 
- Desire meaningful work (Becton et al., 2014; Eisner, 2005; Hershatter \& Epstein, 2010)

- Value work-life balance (Allen, 2004; Barkhuizen, 2014; Bassett, 2008; Eisner, 2005; Finegold et al., 2002; Hershatter \& Epstein, 2010; Mohrman \& Spreitzer, 2002; Twenge, 2010)

- Seek professional growth and development (Allen, 2004; Barkhuizen, 2014; Bassett, 2008; Eisner, 2005; Finegold et al., 2002; Haeberle, Herzberg \& Hobbs, 2009; Hills et al., 2013)

- Prefer project work versus function-based work (Allen, 2004; Eisner, 2005; Haeberle et al., 2009)

- Insist on an open environment and inclusive style of management where they can express their opinion and contribute to decisions (Bassett, 2008; Eisner, 2005; Hershatter \& Epstein, 2010)

- Require frequent feedback (Eisner, 2005; Haeberle et al., 2009; Hershatter \& Epstein, 2010; Hills et al., 2013)

- Expect immediate rewards and recognition for current accomplishments instead of being promised a future reward (Bassett, 2008; Eisner, 2005; Haeberle et al., 2009)

These Millennial work preferences in several instances contrast sharply with the older generations in the workplace. Espinoza and Ukleja (2016) state that the Millennial generation entering the workforce has "starkly different attitudes and desires than employees over the past few decades." As Millennials enter the workforce and advance into positions of power and influence they are beginning to push institutions to accommodate their beliefs and values. For the most part, Baby Boomers have set the rules for today's work expectations. However, as Baby Boomers retire and exit the workforce, the future vitality of organizations is dependent upon attracting, developing and retaining Millennials (Allen, 2004; Espinoza \& Ukleja, 2016; Hershatter \& Epstein, 2010; Twenge, 2010).

Unfortunately, industry is finding that talent management of Millennials is more difficult to accomplish than it was for preceding generations (Espinoza \& Ukleja, 2016; Hershatter \& Epstein, 2010; Hills et al., 2013; Tulgan, 2009). According to research, Millennials switch jobs more than any other generation before them (Barkhuizen, 2014; Bassett, 2008; Becton et al., 2014; Du Plessis et al., 2015; Kim \& Barna Group, 2013; Twenge, 2010). As a result, academic literature and popular press have both indicated that effective talent management of Millennials is becoming a central management issue for organizations (Barkhuizen, 2014; Espinoza \& Ukleja, 2016; Tulgan, 2009).

\section{Retention Literature Review}

Research shows that an employee's desire to remain with an organization is influenced by the employee's perception of support received (Allen et al., 2003; Dawley et al., 2008). Employees can attribute feelings of support to either the organization or their supervisor. These feelings of support then work to increase organizational commitment (Dawley et al., 2008; Hutchison, 1997; Maertz et al., 2007). This next section will review the literature regarding perceptions of support and organizational commitment.

\subsection{Perceived Organizational Support (POS) and affective commitment}

Literature describes the employer-employee relationship as an exchange relationship. In researching this exchange relationship, Eisenberger, Huntington, Hutchison, and Sowa (1986) found that "employees develop global beliefs concerning the extent to which the organization values their contributions and cares about their well-being" (p. 501). In academic literature this is known as perceived organizational support or POS.

Social exchange theory has been commonly used in studies that attempt to better understand the reciprocal relationships that develop between employees and the organization (Allen et al., 2003; Dawley et al., 2008; DeConinck \& Johnson, 2009; Du Plessis et al., 2015; Eisenberger et al., 1986; Eisenberger, Cummings, Armeli, \& Lynch, 1997; Eisenberger et al., 2001; Hutchison, 1997; 
Wayne et al., 1997). According to social exchange theory, employees exhibit positive or negative attitudes and behaviors toward the organization to the same degree they feel the organization either values or does not value their contributions (Eisenberger et al., 1997; Kurtessis et al., 2015; Shore, Tetrick, Lynch, \& Barksdale, 2006; Wayne et al., 1997).

Social exchange theory is based on the reciprocity norm (Gouldner, 1960) which holds as a universal moral norm the belief that people should help those who have helped them. Regarding the employer-employee relationship, the norm of reciprocity states that when an employee perceives high levels of support from either the organization as a whole or from its agents, the employee will feel an obligation to reciprocate that support (Eisenberger et al., 2001; Kurtessis et al., 2015). Research has found that one of the ways employees satisfy this felt indebtedness is through increased organizational commitment (Dawley et. al., 2008; DeConinck \& Johnson, 2009; Eisenberger et al., 1986; Eisenberger et al., 2001; Wayne et al., 1997).

According to social exchange theory, commitment as a two-way street. POS represents the employer side of the exchange and affective commitment represents the employee side. Research findings unanimously support the idea that employees' perception of the organization's commitment to them strongly influences their affective commitment to the organization (Allen et al., 2003; Dawley et al., 2008; DeConinck \& Johnson, 2009; Eisenberger et al., 1986; Eisenberger et al., 2001; Hutchison, 1997; Loi, Hang-yue, \& Foley., 2006; Maertz et al., 2007; Rhoades et al., 2001; Riggle, Edmonson \& Hansen, 2009; Shore et al., 2006; Wayne et al., 1997).

\subsection{Perceived Supervisor Support (PSS) and affective commitment}

Kottke and Sharafinski (1988) added a second component to Eisenberger et al. (1986) concept of how employees develop organizational commitment. They suggested that just as employees form global perceptions concerning the amount of support given to them by the organization, they also develop overall perceptions concerning supervisor support. Recent research supports this, finding that supervisors form individual relationships with employees that are distinct from employee attitudes toward the organization as a whole (Maertz et al., 2007). This second component, known as perceived supervisor support or PSS in academic literature, is defined as an employee's "general views concerning the degree to which supervisors value their contributions and care about their well-being" (Eisenberger et al., 2002, p. 565).

PSS leads to affective commitment through the same ideologies as POS: social exchange and the reciprocity norm. These concepts state that when an employee perceives high levels of investment and care from either the organization as a whole or from its agents, the employee will feel an obligation to reciprocate that support (Eisenberger et al., 2001; Kurtessis et al., 2015). This felt obligation leads employees to reciprocate through organizational citizenship behaviors such as affective commitment (Dawley et. al., 2008; DeConinck \& Johnson, 2009; Eisenberger et al., 1986; Eisenberger et al., 2001; Wayne et al., 1997). When the supervisor and employee both apply the reciprocity norm to their relationship, perceived favorable treatment from either party is reciprocated, leading to a beneficial and positive cycle for both (Rhoades \& Eisenberger, 2002).

Although PSS and POS are highly correlated (DeConinck \& Johnson, 2009; Eisenberger et al., 2002; Rhoades \& Eisenberger, 2002), they have been shown to be distinct constructs (Hutchison, 1997; Kottke \& Sharafinski, 1988; Wayne et al., 1997), both of which are important components of an employee's global perception of support (Kottke \& Sharafinski, 1988).

\subsection{Affective commitment mediates both POS and PSS with turnover intentions}

The literature thus far has indicated that both POS and PSS are associated with increased positive affective commitment. Research also indicates that affective commitment mediates POS and PSS with turnover intentions. Two separate meta-analysis performed by Rhoades and Eisenberger (2002) and Kurtessis et al. (2015) both confirm affective commitment mediates the effects of POS and PSS on turnover intentions. 


\subsection{HRM and Perceived Support}

Recognizing that employee commitment can be enhanced through employee perceptions of support is an important first step in retaining employees. Perhaps even more important though, is understanding practical ways to increase employee perceptions of support. Research shows that for Millennials in several Western societies, core antecedents leading to perceived support are HRM policies and practices that align with the Millennial generation's values and work expectations (Barkhuizen, 2014; Deal et al., 2010; Du Plessis et al., 2015; Smit et al., 2015).

\subsection{Retaining Millennials through HRM}

HRM policies and procedures valued by Millennials have been researched in multiple countries and findings indicate that within Western societies, Millennials are remarkably similar in what they view as important workplace attributes. Studies conducted among Millennials in South Africa found that base salary, work-life balance, career development opportunities, and recognition were the most important reward practices. In addition, working relationships with supervisors were also a crucial retention factor (Barkhuizen, 2014; Smit et al., 2015). Researchers in New Zealand found Millennial employees had strong preferences for recognition, advancement, work-life balance, and a good relationship with their supervisor and peers (Cennamo \& Gardner, 2008). Similarly, among Millennials in Belgium, De Hauw and De Vos (2010) concluded that "expectations regarding job content, training, career development, and financial rewards" are largely embedded within the Millennial generation. Results in the United States revealed Millennials valued having flexible hours and flexible work locations, desired personal development opportunities and regular salary increases, and expected accomplishments to be recognized frequently (Bassett, 2008). Finally, D'Amato and Herzfeldt (2008) researched four generational cohorts across Europe and found younger generations have a strong desire for continuous learning and developmental opportunities. In addition to valuing compensation, work-life balance, and developmental opportunities, Millennials have especially high expectations of their immediate supervisor. Research shows Millennials have a preoccupation with positive, one-on-one attention, and they want managers who will act as mentors and career advocates to help them succeed and develop in their career (Espinoza \& Ukleja, 2016; Hershatter \& Epstein, 2010; Tulgan, 2009). Bassett (2008) found Millennials will trade the security of working for a solid company for a smaller company "if they feel they will have a close personal relationship with the person in charge" (p. 19). Similarly, Barkhuizen (2014) found positive working relationships with supervisors to be the most desired criteria among Millennials in South Africa.

\section{Conceptual Framework}

Based on the literature reviewed regarding the relationships between HRM, POS, PSS, affective commitment and turnover intentions, the following conceptual model is proposed.

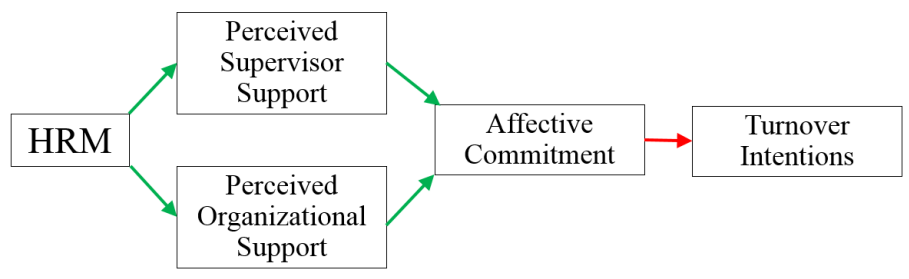

Combining this framework with an understanding of the unique characteristics and work preferences of the Millennial generation will allow organizations to work toward greater retention of Millennial employees. 


\section{Conclusions}

Finding effective solutions for retaining Millennial employees has become a major topic of interest in Western societies. The literature review produced a conceptual framework showing turnover is decreased and organizational commitment is increased when employees feel supported and valued.Key elements that Millennials have identified as creating a feeling of support are organizational policies that promote developmental opportunities, flexible work options, and a worklife balance. Perhaps most important for Millennials is feeling valued and supported by their immediate supervisor. Understanding this framework helps organizations in Western societies to effectively work toward improving retention of their Millennial employees.

Finally, although generational cohorts have been historically defined within national boundaries, the global connectedness of today's population raises the question of whether there are now 'global generations'. Although more research is needed to decisively answer that question, it is interesting to note that research reveals remarkable similarities in the expectations and workplace preferences of Millennials in Western societies such as the United States, Canada, Europe, Australia, and South Africa.

\section{References}

Allen, D. G., Shore, L. M., \& Griffeth, R. W. (2003). The role of perceived organizational support and supportive human resource practices in the turnover process. Journal of Management, 29(1), 99-118. doi:10.1016/S0149-2063(02)00222-2

Allen, P. (2004). Welcoming Y. Benefits Canada, 28(9), 51-56.

Barkhuizen N. (2014). Exploring the importance of rewards as a talent management tool for Generation $Y$ employees. Mediterranean Journal of Social Sciences, 5(27), 1100-1105. doi:10.5901/mjss.2014.v5n27p1100

Barney, J. B. (1991). Firm resources and sustained competitive advantage. Journal of Management, 17, 99-120.

Bassett, B. (2008). Working with Generation Y. OfficePro, 68(2), 16

Becton, J. B., Walker, H. J., \& Jones-Farmer, A. (2014). Generational differences in workplace behavior. Journal of Applied Social Psychology, 44(3), 175-189. doi:10.1111/jasp.12208

Dawley, D., Andrews, M., \& Bucklew, N. (2008). Mentoring, supervisor support, and perceived organizational support: what matters most? Leadership \& Organization Development Journal, 29(3), 235-247.

DeConinck, J., \& Johnson, J. (2009). The effects of perceived supervisor support, perceived organizational support, and organizational justice on turnover among salespeople. Journal of Personal Selling and Sales Management, 29(4), 333-351.

Du Plessis, L. (2010). The relationship between perceived talent management practices, perceived organizational support (POS), perceived supervisor support (PSS) and intention to quit amongst Generation $\mathrm{Y}$ employees in the recruitment sector.

Du Plessis, L., Barkhuizen, N., Stanz, K., \& Schutte, N. (2015). The management side of talent: Causal implications for the retention of Generation Y employees. Journal of Applied Business Research, 31(5), 1767-1780.

Eisenberger R, Armeli S, Rexwinkel B, Lynch P, \& Rhoades L. (2001). Reciprocation of perceived organizational support. The Journal of Applied Psychology, 86(1), 42-51.

Eisenberger, R., Huntington, R., Hutchison, S., \& Sowa, D. (1986). Perceived organizational support. Journal of Applied Psychology, 71(3), 500-507. doi:10.1037//0021-9010.71.3.500

Eisenberger R., Cummings J., Armeli S., \& Lynch P. (1997). Perceived organizational support, discretionary treatment, and job satisfaction. The Journal of Applied Psychology, 82(5), 812-20.

Eisenberger R., Stinglhamber F., Vandenberghe C., Sucharski I., \& Rhoades L. (2002). Perceived supervisor support: Contributions to perceived organizational support and employee retention. The Journal of Applied Psychology, 87(3), 565-73.

Eisner, S. P. (2005). Managing Generation Y. S.A.M. Advanced Management Journal, 70(4), 4

Espinoza, C., \& Ukleja, M. (2016). Managing the Millennials: Discover the core competencies for managing today. John Wiley.

Finegold, D., Mohrman, S., \& Spreitzer, G. (2002). Age effects on the predictors of technical workers' commitment and willingness to turnover. Journal of Organizational Behavior, 23(5), 655-674.

Gouldner, A. W. (1960). The norm of reciprocity: A preliminary statement. American Sociological Review, 25(2), 161-178.

Haeberle, K., Herzberg, J., \& Hobbs, T. (2009). Leading the multigenerational work force. Healthcare Executive, 24(5). 
Hershatter, A., \& Epstein, M. (2010). Millennials and the world of work: An organization and management perspective. Journal of Business and Psychology, 25(2), 211-223. doi:10.1007/s10869-010-9160-y

Hills, C., Ryan, S., Warren-Forward, H., \& Smith, D. (2013). Managing 'Generation Y' occupational therapists: Optimising their potential. Australian Occupational Therapy Journal, 60(4).

Hutchison, S. (1997). A path model of perceived organizational support. Journal of Social Behavior \& Personality, 12(1).

Kim, D. \& Barna Group (2013). 20 and something: Have the time of your life (and figure it all out too). Grand Rapids, Michigan: Zondervan

Kottke, J., \& Sharafinski, C. (1988). Measuring perceived supervisory and organizational support. Educational and Psychological Measurement, 48(4), 1075-1079. doi:10.1177/0013164488484024

Kurtessis, J., Eisenberger, R., Ford, M., Buffardi, L., Stewart, K., \& Adis, C. (2015). Perceived organizational support: A meta-analytic evaluation of organizational support theory. Journal of Management. doi:10.1177/0149206315575554

Loi, R., Hang-yue, N., \& Foley, S. (2006). Linking employees' justice perceptions to organizational commitment and intention to leave: The mediating role of perceived organizational support. Journal of Occupational and Organizational Psychology, 79(1), 101-120.

Maertz, C., Griffeth, R., Campbell, N., \& Allen, D. (2007). The effects of perceived organizational support and perceived supervisor support on employee turnover. Journal of Organizational Behavior, 28(8), 10591075. doi:10.1002/job.472

Mannheim, K. (1952). Essays on the sociology of knowledge (The international library of sociology and social reconstruction). London: Routledge \& K. Paul.

Meyer, J. \& Allen, N. (1991). A three-component conceptualization of organizational commitment. Human Resource Management Review, 1(1), 61-89. doi:10.1016/1053-4822(91)90011-Z

Rhoades L, Eisenberger R, \& Armeli S. (2001). Affective commitment to the organization: The contribution of perceived organizational support. The Journal of Applied Psychology, 86(5), 825-36.

Rhoades L, \& Eisenberger R. (2002). Perceived organizational support: A review of the literature. The Journal of Applied Psychology, 87(4), 698-714.

Riggle, R., Edmondson, D., \& Hansen, J. (2009). A meta-analysis of the relationship between perceived organizational support and job outcomes: 20 years of research. Journal of Business Research, 62(10), 1027-1030. doi:10.1016/j.jbusres.2008.05.003

Shore, L., Tetrick, L., Lynch, P., \& Barksdale, K. (2006). Social and economic exchange: Construct development and validation. Journal of Applied Social Psychology, 36(4), 837-867. doi:10.1111/j.00219029.2006.00046.x

Smit, W., Stanz, K., \& Bussin, M. (2015). Retention preferences and the relationship between total rewards, perceived organizational support and perceived supervisor support. Journal of Human Resource Management, 13(1), 1-13. doi:10.4102/sajhrm.v13i1.665

Tulgan, B. (2009). Not everyone gets a trophy: How to manage Generation Y. San Francisco, CA: JosseyBass.

Twenge, J. (2010). A review of the empirical evidence on generational differences in work attitudes. Journal of Business and Psychology, 25(2), 201-210.

Twenge, J., \& Campbell, S. (2008). Generational differences in psychological traits and their impact on the workplace. Journal of Managerial Psychology, 23(8), 862-877.

Twenge, J., Campbell, S., Hoffman, B., \& Lance, C. (2010). Generational differences in work values: Leisure and extrinsic values increasing, social and intrinsic values decreasing. Journal of Management, 36(5), $1117-1142$.

Wayne, S., Shore, L., \& Liden, R. (1997). Perceived organizational support and leader-member exchange: A social exchange perspective. Academy of Management Journal, 40(1), 82. 